\title{
French Adaptation of the Activity Impairment Assessment Score in Order to Assess the Activity Impairment of Women Presenting with Acute Uncomplicated Cystitis in Primary Care: Translation and Psychometric Validation.
}

Yves-Marie VINCENT ( $\nabla$ vincent.yvesmarie@gmail.com )

Universite de Bordeaux https://orcid.org/0000-0001-5716-6931

Mélanie Duhart

Universite de Bordeaux

Alain Chen Yen Su

Universite de Bordeaux

Jean-Arthur Micoulau-Franchi

Universite de Bordeaux

Guillaume Conort

Universite de Bordeaux

\section{Research}

Keywords: urinary tract infections, quality of life, activities of daily living, cross-cultural adaptation, psychometrics, primary care

Posted Date: May 4th, 2020

DOI: https://doi.org/10.21203/rs.3.rs-25577/v1

License: (c) (i) This work is licensed under a Creative Commons Attribution 4.0 International License. Read Full License 


\section{Abstract}

\section{Purpose}

The Activity Impairment Assessment (AIA) is a 5 items questionnaire exploring the impact of acute cystitis on daily activities. It's a self-administrated tool easy to use in primary care studies. The purpose of this study is to translate and validate a French version of the AIA: the AIA-fr.

\section{Methods}

We use a forward-backward translation before to analyze the psychometric properties of the French version. We proceeded to a quantitative, prospective, observational multicentric study. King Health Questionnaire and Ditrovie scale were used to determine convergent and divergent validity. Following an inclusion visit, each file was completed by the patient on day 0,3 and 5 .

\section{Results}

Fifty-two files were received by the investigator of which two empty files. In the end, 50 files were included in the study. There was a $100 \%$ response rate for the AIA-fr on days 0, 3 and 5. Cronbach's alpha was calculated at 0.87 with a $95 \%$ confidence interval between 0.78 and 0.92 . We found that this coefficient was not improved by removing one of the items (Cronbach's alpha $0.81-0.87$ ). There is a negative correlation ( $p=0.01$ Rs $=-0.35$ ) between the total AIA-fr score and the number of days between symptom onset and consultation (day 0 ). This implies that the higher the AIA-fr score the sooner women will seek medical care.

\section{Conclusions}

The French version of the AIA is a psychometrically acceptable self-report questionnaire for measuring the impact of acute cystitis on daily activities. It's the first French tool evaluating this impact.

\section{Background}

Urinary tract infections (UTI) are a very common condition seen by general practitioners and one of the most frequent bacterial infections [1]. Among UTI, Acute Uncomplicated Cystitits (AUC) are seen as mild infections but their impact can be quite significant on patient quality of life (QoL) [2].

Recent studies suggest that work on UAC should include the impact of these symptoms on the patient's daily life in order to classify uncomplicated urinary tract infections (UUTIs) according to the impact on QoL. This type of classification could help to look at alternatives to antibiotics such as symptomatic treatment options [3-4]. This study is made all the more relevant by the fact that there is no scientifically proven risk of severe medical complication (sepsis, pyelonephritis) of not treating all UACs with antibiotics. There is however scientific proof of non-inferiority of the use of painkillers versus antibiotics 
on symptom relief when those are mild to moderate [3]. Frequent side effects caused by antibiotics must also count in the decision-making process [5].

Using the patient's experience of her symptoms as a parameter when choosing UAC treatment options is a way of implementing shared decision making. Several studies highlight patients' wish to take part in the treatment of UTIs [6], and that their implication directly and positively impacts symptom and affection experience [7]. This being said, the development of tools assessing the personal experience and impact of UTI symptoms comes forward as a key to improving clinical practice guidelines.

Tools used in this field at an international level should be identical to enable researchers in various countries to corroborate results giving them more scientific weight: a global tool to address a global problematic in essence. The best approach for french research is to translate an existing and validated tool from English to French in order to export this tool to the french speaking world and widen its accessibility.

We chose the Activity Impairment Assessment (AIA) scale [8]. It's a self-administered questionnaire of which each of the five items is answered on a Likert-type scale. It was validated by a clinical trial assessing the efficacy of sustained-release ciprofloxacine in the treatment of uUTIs. Bayer, the trial promoter, has even kept its copyrights on the scale. It has already been translated in latin american spanish. The self-reporting aspect of the scale gives it greater precision on daily life impact [9] and selfadministration annuls interpretation bias due to completion by a third party.

The aim of this study is to offer a French translation of the AIA, to explore its psychometric characteristics to determine wether it is a valid and reliable tool for the measurment of the impact of UAC in the daily life of women seeking primary medical care in France.

\section{Methods}

\subsection{Participants}

Patients were recruited when visiting their physicians. We formed a group of 23 volonteer, non specialised general practicioners from independent practices in the same region of France. From July 2017, five recruitment files were given out to each practicioner. Each patient visiting for symptoms of UAC as defined by the SPILF (French speaking infectious diseases society) would be asked wether she agreed to participate in an anonymous study. If she was interested, a written information sheet was given out to her before acquiring her consent as required by the CNIL (national commission in charge of individual liberties regarding information technology). The recruiting doctor then contacted the investigator to transfer the patient's telephone details and her recruitment file's reference code.

\subsection{Procedure}

We proceeded to a quantitative, prospective, observational multicentric study. Following an inclusion visit, each file was independently hand-completed by the patient on day 0, 3 and 5. A stamped envelope was 
included in the file so the patient could send her file to the study's main investigator. We chose to gather similar information as the ones used for the validation of the original english version of the questionnaire. The general patient characteristics were gathered on day 0 : age, socio-economic group, years of education, living area, physical activity according to the Marshall score, uUTI history, number of days since onset of UAC symptoms before seeing physician, use of a disptick on day 0 . The symptoms' severity was controlled on day 0,3 and 5 using a list of 13 symptoms scored from 0 to 3 . This symptom list was taken from a tool elaborated by a Danish study [10] using a review of literature and patient interviews in order to assess, among others, the severity of symptoms in UTIs. The following scales were filled in by patients on day 03 and 5 : the french version of the AIA, the King's health Questionnaire (KHQ) [11]. The Ditrovie scale [12] was answered on day 5. In order to answer any questions and limit the number of patients lost to follow-up, the main investigator would call each patient between day 0 and day 3 and send a text message reminder after day 5 .

\subsubsection{Questioners used}

The KHQ measures the QoL of female patients presenting urinary incontinence. It is made up of 21 items answered via a 4 to 5 point Likert scale that adds up to a score out of a hundred. These items are divided in nine categories to assess the impact of the UTI on the patient's QoL. The 10th category concerns symptom severity and was not used in this study.

The Ditrovie scale assesses the impact of urinary incontinence by urgency over the last 4 weeks. It is made up of 10 items scored from 1 to 5 .

\subsection{French version of AIA \\ 2.3.1. Translation/back translation}

Before translating the AIA scale we asked for authorization from the authors of the original English article. They agreed to it under the condition that we used a translation/back translation method. We therefore had to undergo several steps from june to july 2017. The initial version was first translated from english to french independently and separately by 3 english speaking francophones of which 2 doctors in translatology. These translations were combined into a unique version by a committee composed of medical interns, doctors and translaters. The combined version was then back translated by 2 french speaking anglophones, both doctors in their fields of study in english and having not participated in the study until then. After the back-translation another committee put together a pre-version of the french AIA. The pre-version was tested on 12 patients to check its understandability and note any substantive comments. The comments on the pre-test lead to adjustments by a third and last committee thereby validating the final version of the translated scale baptised AIA-fr.

\subsubsection{Scoring}

The original AIA scoring method was applied. We kept the 0 to 4 points Likert scale with an identical numeric distance between each of the 5 possible answers. 


\subsubsection{Statistical methods and hypotheses}

Data was analysed according to the classical test theory with the R software. The distribution of scores gathered using the AIA-fr was studied visually and numerically by a Kolmogorov-Smirnov test. Non parametric tests were used when data followed a non-normal distribution. A significance threshold of 0.05 was used for all the statistical analysis in this study. We used the same hypothesis as the original AlA version.

\subsubsection{Study of the quality of the items}

We looked to define the quality of the items recorded on day 0 according to 3 criteria : the non-response rate, the search of a visual floor or ceiling effect on a distribution diagram, the search for redundancies between items using Spearman's correlation coefficients.

\subsubsection{Structural analysis}

We lead a principal component analysis on all of the day 0 answers to the 5 AIA items in our patient sample in order to analyse the structural validity of the test.

\subsubsection{Reliability}

The tool's reliability was measured as an internal consistancy coefficient : Cronbach's alpha. It was set as superior or equal to 0.8 to ensure minimal measurement error.

\subsubsection{Validity}

\section{convergent and divergent validity}

To measure convergent and divergent validity, we calcuated a Spearman correlation coefficient between the day 0 AlA-fr total score, the day $0 \mathrm{KHQ}$ answers and the day 5 Ditrovie scale answers.

A statistically significant $(p<0.05)$ high correlation $(R s>0.4)$ is expected between the AIA scores and the items contributing to convergent validity according to the investigators (domains 3,4 and 5 of the KHQ : daily activity, social and physical limitations; and items 1,2 and 4 of the Ditrovie scale). Conversely, items judged by the investigators as contributing to divergent validity are expected to have a low, non significant correlation (domains 6,7 and 8 of KHQ : private life, émotions, sleep/energy level ; items $5,6,7,9,10$ of the Ditrovie scale).

\section{discriminant validity}

We studied the discriminant validity of the test using the original version's validation method by comparing subgroups of AIA-fr scores on day 0 according to the symptom severity on day 0 using a Kruskal Wallis test. Like the authors of the original AIA version, we speculated a good discrimination of the different levels of severity of symptoms by the AIA-fr. 


\subsubsection{Responsiveness}

It was speculated that the more the total AIA-fr score improved between day 0 and day 5 the more the symptoms improved between day 0 and day 5 .

We studied the joint evolving dynamic between symptom severity and total AIA-fr score by conducting a Kruskal Wallis test for each symptom to compare the mean change for each of the two deltas, i.e for the severity score and for the total AIA-fr between day 0 and day 5 .

\section{Results}

\subsection{Sample characteristics}

Seventy one patients were recruited to the study during medical visits over the period of august 2017 to december 2017. Two patients were excluded because their diagnosis was requalified as pyelonephritis. Fifty two files were recieved by the investigator of which two empty files. In the end, 50 files were included in the study.

The patient's mean age was 44.6 years old with two peaks in age distribution : one around 20 years old and one at peri menopause around 48-52 years old. Concerning socio-economic categories, $68 \%$ of patients reported a professionnal activity with a majority of them as employees and varying levels of training. Thirty one patients (62\%) were living in a mainly rural area and nineteen patients (38\%) in a mainly urban area.

A large majority of patients (62\%) was defined as sedentary (Marshall score between 0 and 3 ).

Most of them (88\%) had a history of at least one uUTI.

Urinary symptoms had started on average 3.56 days before inclusion (with a range of 1 to 30 days). Only 7 patients (14\%) had a urinary stick done.

On day 0 more than half of the patients gave the highest score for the following symptoms : "pain while urinating » (60\% gave a severity score of 3$)$, « increased frequency of urination during the day » $(62 \%)$, " increased urge to urinate » $(72 \%)$, « need to hurry to the toilet » $(54 \%)$, and « burning sensation while urinating " $(62 \%)$. On the other hand more than half of the patients gave a score of zero for « involuntary leakage of urine » (60\% gave a severity score of 0$)$ and « blood in the urine » $(64 \%)$.

\subsection{Validation}

\subsubsection{Data distribution and quality of the items}

There was a $100 \%$ response rate for the AIA-fr on days 0,3 and 5 On day 0 patients used the full range of answers for each item with a mean answer of 1 (« a little of the time») (Fig. 3) for all 5 items. Five 
patients $(10 \%)$ declared a limitation score of zero at inclusion.

Visually, the range of AIA-fr total scores on day 0 showed a non-normal distribution. This was confirmed by a Kolmogorov-Smirnov test $(\mathrm{P}<2.2 \mathrm{e}-16)$.

The distribution of answers to each item of the AIA-fr on day 0 showed a slight floor effect on the first item (« cut down on amount of time spent at work or other activities »)(Table 4).

Table 1

Distribution of AIA-fr responses to each individual item at J0

\begin{tabular}{|lllll|}
\hline AlA items & Mean (SD) & median & Min-Max & Theorical range \\
\hline $\mathrm{N}^{\circ} 1$ & $1,04(1,19)$ & 1 & $0-4$ & $0-4$ \\
\hline $\mathrm{N}^{\circ} 2$ & $1,30(1,15)$ & 1 & $0-4$ & $0-4$ \\
\hline $\mathrm{N}^{\circ} 3$ & $1,46(1,15)$ & 1 & $0-4$ & $0-4$ \\
$\mathrm{~N}^{\circ} 4$ & $1,28(1,14)$ & 1 & $0-4$ & $0-4$ \\
$\mathrm{~N}^{\circ} 5$ & $1,44(1,31)$ & 1 & $0-4$ & $0-4$ \\
\hline Total score & $6,52(4,82)$ & 5 & $0-17$ & $0-20$ \\
\hline
\end{tabular}


Table 4

Mean (SD) AlA-fr change scores by degree of symptom change

\begin{tabular}{|c|c|c|c|c|}
\hline symptom & $\begin{array}{l}\text { Change in severity } \\
\text { score } \\
\text { (J5-J0) }\end{array}$ & $\mathbf{N}$ & $\begin{array}{l}\text { Mean } \\
\text { (SD) }\end{array}$ & p-value \\
\hline \multirow[t]{5}{*}{ 1. Pain while urinating } & -3 & 22 & 6.41 & \multirow[t]{5}{*}{0.08031} \\
\hline & -2 & 17 & $(4.4 \%)$ & \\
\hline & -1 & 5 & $\begin{array}{l}7.47 \\
(5.04)\end{array}$ & \\
\hline & \multirow[t]{2}{*}{0} & \multirow[t]{2}{*}{3} & $\begin{array}{l}3.80 \\
(2.28)\end{array}$ & \\
\hline & & & $2.00(2.0)$ & \\
\hline \multirow[t]{6}{*}{ 2. Difficulty emptying the bladder } & -3 & 9 & \multirow{2}{*}{$\begin{array}{l}7.33 \\
(4.69)\end{array}$} & \multirow{6}{*}{$\begin{array}{l}0.03646 \\
*\end{array}$} \\
\hline & -2 & 13 & & \\
\hline & -1 & 10 & $(4.80)$ & \\
\hline & 0 & 13 & $\begin{array}{l}7.50 \\
(5.19)\end{array}$ & \\
\hline & \multirow[t]{2}{*}{1} & \multirow[t]{2}{*}{2} & $\begin{array}{l}3.15 \\
(2.34)\end{array}$ & \\
\hline & & & $\begin{array}{l}5.50 \\
(4.95)\end{array}$ & \\
\hline \multirow{6}{*}{$\begin{array}{l}\text { 3. Uncomfortable pressure around the } \\
\text { bladder }\end{array}$} & -3 & 18 & \multirow{2}{*}{$\begin{array}{l}6.44 \\
(5.16)\end{array}$} & \multirow[t]{6}{*}{0.2211} \\
\hline & -2 & 15 & & \\
\hline & -1 & 8 & $\begin{array}{l}7.47 \\
(3.80)\end{array}$ & \\
\hline & 0 & 5 & $\begin{array}{l}3.62 \\
(3.07)\end{array}$ & \\
\hline & \multirow[t]{2}{*}{1} & \multirow[t]{2}{*}{1} & $\begin{array}{l}6.80 \\
(6.06)\end{array}$ & \\
\hline & & & 2.00 (NA) & \\
\hline
\end{tabular}

\negative score $=$ improvement $;$ positive score $=$ deterioration 


\begin{tabular}{|c|c|c|c|c|}
\hline symptom & $\begin{array}{l}\text { Change in severity } \\
\text { score } \\
\text { (J5-J0) }\end{array}$ & $\mathbf{N}$ & $\begin{array}{l}\text { Mean } \\
\text { (SD) }\end{array}$ & $\mathrm{p}$-value \\
\hline \multirow[t]{5}{*}{$\begin{array}{l}\text { 4. Increased frequency of urination during } \\
\text { the day }\end{array}$} & -3 & 22 & $\begin{array}{l}7.36 \\
(4.54)\end{array}$ & \multirow[t]{5}{*}{0.05549} \\
\hline & -2 & 14 & \multirow{2}{*}{$\begin{array}{l}5.57 \\
(4.67)\end{array}$} & \\
\hline & -1 & 5 & & \\
\hline & \multirow[t]{2}{*}{0} & \multirow[t]{2}{*}{6} & $\begin{array}{l}7.40 \\
(3.65)\end{array}$ & \\
\hline & & & $\begin{array}{l}2.67 \\
(3.93)\end{array}$ & \\
\hline \multirow[t]{5}{*}{ 5. Increased urge to urinate } & -3 & 27 & \multirow{2}{*}{$\begin{array}{l}7.63 \\
(4.60)\end{array}$} & \multirow{5}{*}{$\begin{array}{l}0.008169 \\
\star \star\end{array}$} \\
\hline & -2 & 12 & & \\
\hline & -1 & 3 & $\begin{array}{l}5.67 \\
(4.25)\end{array}$ & \\
\hline & \multirow[t]{2}{*}{0} & \multirow[t]{2}{*}{5} & $\begin{array}{l}4.33 \\
(2.08)\end{array}$ & \\
\hline & & & $\begin{array}{l}1.20 \\
(1.79)\end{array}$ & \\
\hline \multirow[t]{5}{*}{ 6. Need to hurry to go to the toilet } & -3 & 18 & \multirow{2}{*}{$\begin{array}{l}8.06 \\
(5.60)\end{array}$} & \multirow{5}{*}{$\begin{array}{l}0.03481 \\
\star\end{array}$} \\
\hline & -2 & 15 & & \\
\hline & -1 & 9 & $\begin{array}{l}6.67 \\
(3.22)\end{array}$ & \\
\hline & \multirow[t]{2}{*}{0} & \multirow[t]{2}{*}{5} & $\begin{array}{l}3.78 \\
(3.35)\end{array}$ & \\
\hline & & & $\begin{array}{l}2.80 \\
(2.28)\end{array}$ & \\
\hline \multirow[t]{5}{*}{ 7. Involuntary leakage of urine } & -3 & 2 & \multirow{2}{*}{$\begin{array}{l}8.50 \\
(3.54)\end{array}$} & \multirow[t]{5}{*}{0.2296} \\
\hline & -2 & 6 & & \\
\hline & -1 & 10 & $\begin{array}{l}9.17 \\
(6.11)\end{array}$ & \\
\hline & \multirow[t]{2}{*}{0} & \multirow[t]{2}{*}{29} & $\begin{array}{l}6.50 \\
(5.02)\end{array}$ & \\
\hline & & & $\begin{array}{l}5.38 \\
(4.03)\end{array}$ & \\
\hline
\end{tabular}

\negative score $=$ improvement ; positive score = deterioration 


\begin{tabular}{|c|c|c|c|c|}
\hline symptom & $\begin{array}{l}\text { Change in severity } \\
\text { score } \\
\text { (J5-J0) }\end{array}$ & $\mathbf{N}$ & $\begin{array}{l}\text { Mean } \\
\text { (SD) }\end{array}$ & p-value \\
\hline \multirow[t]{5}{*}{ 8. Burning sensation while urinating } & -3 & 24 & \multirow{2}{*}{$\begin{array}{l}6.17 \\
(4.42)\end{array}$} & \multirow[t]{5}{*}{0.5987} \\
\hline & -2 & 13 & & \\
\hline & -1 & 4 & $\begin{array}{l}6.69 \\
(4.77)\end{array}$ & \\
\hline & \multirow[t]{2}{*}{0} & \multirow[t]{2}{*}{6} & $\begin{array}{l}8.00 \\
(6.98)\end{array}$ & \\
\hline & & & $\begin{array}{l}4.33 \\
(3.44)\end{array}$ & \\
\hline \multirow[t]{7}{*}{ 9. Smelly urine } & -3 & 9 & \multirow{2}{*}{$\begin{array}{l}6.44 \\
(3.47)\end{array}$} & \multirow[t]{7}{*}{0.1456} \\
\hline & -2 & 4 & & \\
\hline & -1 & 11 & $\begin{array}{l}10.75 \\
(4.50)\end{array}$ & \\
\hline & 0 & 22 & \multirow{2}{*}{$\begin{array}{l}5.36 \\
(4.13)\end{array}$} & \\
\hline & \multirow[t]{3}{*}{1} & \multirow[t]{3}{*}{1} & & \\
\hline & & & $\begin{array}{l}5.95 \\
(5.01)\end{array}$ & \\
\hline & & & 2.00 (NA) & \\
\hline \multirow[t]{7}{*}{ 10. Change in appearance of urine } & -3 & 8 & \multirow{2}{*}{$\begin{array}{l}6.62 \\
(5.37)\end{array}$} & \multirow[t]{7}{*}{0.8442} \\
\hline & -2 & 10 & & \\
\hline & -1 & 15 & $\begin{array}{l}6.40 \\
(4.84)\end{array}$ & \\
\hline & 0 & 13 & \multirow{2}{*}{$\begin{array}{l}6.00 \\
(2.73)\end{array}$} & \\
\hline & \multirow[t]{3}{*}{1} & \multirow[t]{3}{*}{1} & & \\
\hline & & & $\begin{array}{l}0.46 \\
(5.97)\end{array}$ & \\
\hline & & & 2.00 (NA) & \\
\hline \multirow[t]{5}{*}{ 11. Blood in the urine } & -3 & 7 & \multirow{2}{*}{$\begin{array}{l}6.86 \\
(4.88)\end{array}$} & \multirow[t]{5}{*}{0.4127} \\
\hline & -2 & 4 & & \\
\hline & -1 & 6 & $\begin{array}{l}3.75 \\
(2.36)\end{array}$ & \\
\hline & \multirow[t]{2}{*}{0} & \multirow[t]{2}{*}{30} & $\begin{array}{l}8.00 \\
(5.18)\end{array}$ & \\
\hline & & & $\begin{array}{l}6.07 \\
(4.64)\end{array}$ & \\
\hline
\end{tabular}

\negative score $=$ improvement $;$ positive score $=$ deterioration 


\begin{tabular}{|c|c|c|c|c|}
\hline symptom & $\begin{array}{l}\text { Change in severity } \\
\text { score } \\
\text { (J5-J0) }\end{array}$ & $\mathbf{N}$ & $\begin{array}{l}\text { Mean } \\
(\mathrm{SD})\end{array}$ & p-value \\
\hline \multirow[t]{6}{*}{$\begin{array}{l}\text { 12. Increased frequency of urination at } \\
\text { night }\end{array}$} & -3 & 10 & \multirow{2}{*}{$\begin{array}{l}7.10 \\
(5.76)\end{array}$} & \multirow[t]{6}{*}{0.8621} \\
\hline & -2 & 9 & & \\
\hline & -1 & 13 & $\begin{array}{l}7.44 \\
(4.56)\end{array}$ & \\
\hline & 0 & 13 & $\begin{array}{l}5.85 \\
(4.36)\end{array}$ & \\
\hline & \multirow[t]{2}{*}{1} & \multirow[t]{2}{*}{2} & $\begin{array}{l}5.31 \\
(4.25)\end{array}$ & \\
\hline & & & $\begin{array}{l}5.00 \\
(4.24)\end{array}$ & \\
\hline \multirow[t]{6}{*}{ 13.Pain around the bladder } & -3 & 15 & \multirow{2}{*}{$\begin{array}{l}6.27 \\
(4.56)\end{array}$} & 0.04994 \\
\hline & -2 & 13 & & * \\
\hline & -1 & 10 & $\begin{array}{l}8.92 \\
(4.39)\end{array}$ & \\
\hline & 0 & 8 & $\begin{array}{l}4.60 \\
(4.72)\end{array}$ & \\
\hline & \multirow[t]{2}{*}{1} & \multirow[t]{2}{*}{1} & $\begin{array}{l}4.38 \\
(3.29)\end{array}$ & \\
\hline & & & 2.00 (NA) & \\
\hline
\end{tabular}

When looking for correlation between items we found a certain level of redundancy between item 2 (accomplished less than you would like) and item 3 (were limited in the kind of work or other activity) as shown by a statistically significant correlation ( $R s=0.853$ and $p=3.871589 \mathrm{e}-15$ ).

\subsubsection{Association of AIA-fr total score with sample characteristics}

There was no statistical association between the AIA-fr total scores and age, socio-economic group, years of study, living area, physical activity and history of uUTI.

There is however a negative correlation $(p=0.01136 \mathrm{Rs}=-0.3552159)$ between the total AIA-fr score and the number of days between symptom onset and consultation (day 0 ).

\subsubsection{Structural Analysis}

The Diagram of Eigenvalues (Fig. 2) obtained using principal component analysis puts forward one main dimension that accounts for $67 \%$ of the initial data variance (in other words all 5 item answers of the AIA- 
fr for each of the 50 patients on day 0 ).

\subsubsection{Reliability}

Cronbach's alpha was calculated at 0.87 with a $95 \%$ confidence interval between 0.78 and 0.92 . We found that this coefficient was not improved by removing one of the items (Cronbach's alpha 0.81-0.87).

\subsubsection{Validity}

\subsubsection{Convergent and divergent validity}

There was little difference between the hypothetised correlations and those actually found between the AIA-fr measurements and the corresponding items and domains of KHQ and Ditrovie scale measurements (Table 2).

Table 2

Convergent and divergent validity

\begin{tabular}{|lll|}
\hline & Correlation coefficient & p-value \\
& Rs & \\
\hline KHQ domain 3 - limitation in daily activities & AlA-fr tot & \\
\hline KHQ domain 4 - physical limitations & 0,68 & 4,545 e-08 \\
\hline KHQ domain 5 - social limitations & 0,65 & 4,082 e-07 \\
\hline KHQ domain 6 - private life & 0,63 & $1,058 \mathrm{e}-06$ \\
\hline KHQ domain 7 - emotions & 0,32 & 0,02257 \\
\hline KHQ domain 8 - sleep/energy & 0,27 & 0,06094 \\
\hline Ditrovie item 1 - discomfort outside the home & 0,49 & 0,0002643 \\
\hline Ditrovie item 2 - limitation for grocery shopping & 0,25 & 0,07529 \\
\hline Ditrovie item 4 - frequently interrupted work or daily activities & 0,40 & 0,0004957 \\
\hline Ditrovie item 5 - feeling of shame, of being degraded & 0,09 & 0,003948 \\
\hline Ditrovie item 6 - fear of bad smells & 0,47 & 0,5448 \\
\hline Ditrovie item 7 - losing patience & 0,10 & 0,4717 \\
\hline Ditrovie item 9 - frequent urination during nightime & 0,29 & 0,0373 \\
\hline Ditrovie item 10 - global quality of life & 0,11 & 0,3179 \\
\hline
\end{tabular}


There is a stastistically significant correlation between the AIA-fr total and the $3 \mathrm{KHQ}$ domains selected by the investigators as contributing to convergent validity (daily activity/social/physical limitations) and between the AIA-fr total and items 2 (limitation for grocery shopping) and 4 (frequently interrupted work or daily activities) of the Ditrovie scale.

Divergent validity is confirmed by a low, statistically non-significant association between the AIA-fr total et most Ditrovie scale items and between the AIA-fr total and domain 7 of the KHQ (emotions).

\subsubsection{Discriminant Validity}

For a number of symptoms, there are important differences in AIA-fr total score according to the degree of severity; that is, the worse the symptoms as evaluated by the patient, the higher the total AIA-fr score (Table 3). Symptoms for which the AIA-fr shows effective discrimination in severity are: « difficulty emptying bladder», « increased urge to urinate» and " pain around bladder ». 
Table 3

discriminant validity of the AIA-fr - mean scores by clinical evaluation of 13 symptoms

Symptom

Mean AIA-fr total score by clinical evaluation

p-value

$\begin{array}{llll}0 & 1 & 2 & 3\end{array}$

1. Pain while urinating

4,00

2,50

6,82

6,70

0.572

2. Difficulty emptying the bladder

3,86

8,17

7,14

7,40

0.04752

*

3. Uncomfortable pressure around the

7,00

4,00

6,50

7,22

0.3403 bladder

4. Increased frequency of urination during the day

5. Increased urge to urinate

3,33

6,25

5,92

7,10

0.4109

0,00

2,00

5,20

7,44

0.03183

$\star$

6. Need to hurry to go to the toilet

2,67

5,00

6,30

7,59

0.1857

7. Involuntary leakage of urine

5,93

5,50

9,00

8,00

0.4901

8. Burning sensation while urinating

9,33

8,00

6,92

5,94

0.6837

9. Smelly urine

6,59

5,33

7,67

7,10

0.7129

10. Change in appearance of urine

6,00

6,60

6,80

6,90

0.7841

11. Blood in the urine

6,34

8,00

3,75

7,43

0.5269

12. Increased frequency of urination at night

13.Pain around the bladder

5,80

5,58

8,10

7,00

0.5568

3,43

4,36

9,14

7,00

0.009434

$\star \star$

\subsubsection{Responsiveness}

The AIA-fr total shows statistically significant sensibility in clinical evaluation of symptom evolution for « difficulty emptying bladder» $(p=0.03646)$, « increased urge to urinate» $(p=0.008169)$, « need to hurry to the toilet » $(p=0.03481)$ and « pain around bladder » $(p=0.04994)$ (Table 4$)$. For those symptoms the more the symptoms improved, the more the limitations improved as shown by the AIA-fr score.

\section{Discussion}

This translation was conducted with a rigorous translation/back translation method as per the latest protocols and involved many translation professionals. Standard methodology was also used for the psychometric validation of the scale and gave satisfactory results. 
We found that the higher the AIA-fr score the sooner women will seek medical care

The meaning of each item and its english to french equivalence was widely discussed during the translating process. Using the same psychometric analysis method for the AIA-fr as was used for the original version shows that the results were similar and robust despite a few imperfections. The translation/back translation process pointed out the fact that the english AIA items were very similar to items from the « 36-Item Short Form Health Survey » (SF-36) [13], an english self-administered questionnaire that evaluates the impact of health issues on different aspects of daily life. We chose to translate independently from the french version of the SF-36 for some items and the validation of our translation confirmed its satisfactory psychometric caracteristics with respect to the AIA. We did not look into prior definition of the attribute measured by our tool because our aim was simply to translate an existing, already defined questionnaire. In hindsight, the conceptual model behind the AIA-fr seems to belong to the field of handicap. Still the AIA-fr's one dimensional measurement is pertinent as it is conceived for primary care research and not for clinical practice. In order to better the discriminating power of each item, this study could be extended to an item response theory model.

One of the limitations of this translation is that the psychometric validation used scales that look at the impact of urinary incontinence although they relate to another condition than the one studied. This limitation was however inevitable as there are no specific scales to study the impact of AUC. This reinforces the relevance of the study as the scale that we translated becomes the first and only available specific tool to measure the impact of UTIs in french.

The fact that the impact is only measured on one dimension may limit the scope of the questionnaire but it does allow for a less subjective analysis than describing one's perception of a symptom thereby improving its quantification. Keeping to one dimension also shortens the questionnaire making it more practical to use as illustrated by the $100 \%$ response rate on day 0,3 and 5 of the AIA-fr. This being said a multi-dimensional questionnaire with the same qualities would still be an interesting prospect.

\section{Conclusion}

In conclusion, we translated the english AIA scale into a french version called AIA-fr. This reinforces the scales transculturality following its previous latin american spanish translation. It is the first tool available in french that looks at the functional impact of UUTI on women's daily activities. It will thereby enable researchers to include a new validated score when studying UTIs in french speaking countries in addition to allowing for international comparison. It also sends out a strong message from the scientific community that research is showing more interest in the impact and perception of all types of diseases and their symptoms.

\section{Abbreviations}

AIA

Page 15/19 
Activity Impairment Assessment

AUC

Acute Uncomplicated Cystitis

$\mathrm{KHQ}$

King's health Questionnaire

Qol

Quality of life

SF-36

36-Item Short Form Health Survey

UTI

Urinary tract infections

uUTIs

uncomplicated urinary tract infections

\section{Declarations}

\section{Ethics approval and consent to participate}

We have the agree of the French CNIL (Commission Nationale de l'Informatique et des Libertés) for our work. Our Referent was Chantal Durand from the $\mathrm{CHU}$ of Bordeaux

\section{Consent for publication}

Not applicable

\section{Availability of data and materials}

The datasets analysed during the current study are available from the corresponding author on reasonable request.

\section{Funding}

There was no funding for this study

\section{Competing interests}

The authors declare that they have no competing interests. 


\section{Authors' contributions}

ACYS and YMV were in charge of translation part, while MD and GC built the validation study design. MD was responsible of organization and collecting data. GC performed the statistical analysis. JAMC provided methodological support. All authors participated drafting the manuscript.

\section{Acknowledgments}

Special thanks to physician recruiter for volunteer participation and to all patients who took the time to participate in this study.

\section{References}

1. François M, Hanslik T, Dervaux B, Le Strat $Y$, Souty $C$, Vaux S, et al. The economic burden of urinary tract infections in women visiting general practices in France: a cross-sectional survey. BMC Health Serv Res. 2016;09(a):365. 16(.

2. Ellis $A K$, Verma S. Quality of life in women with urinary tract infections: is benign disease a misnomer? J Am Board Fam Pract déc. 2000;13(6):392-7.

3. Gágyor I, Bleidorn J, Kochen MM, Schmiemann G, Wegscheider K, Hummers-Pradier E. Ibuprofen versus fosfomycin for uncomplicated urinary tract infection in women: randomised controlled trial. BMJ. 23 déc 2015;351:h6544.

4. Little P, Moore MV, Turner S, Rumsby K, Warner G, Lowes JA, et al. Effectiveness of five different approaches in management of urinary tract infection: randomised controlled trial. BMJ. 5 févr 2010;340:c199.

5. Ernst EJ, Ernst ME, Hoehns JD, Bergus GR. Women's quality of life is decreased by acute cystitis and antibiotic adverse effects associated with treatment. Health Qual Life Outcomes 27 juill. 2005;3:45.

6. Duane S, Domegan C, Callan A, Galvin S, Cormican M, Bennett K, et al. Using qualitative insights to change practice: exploring the culture of antibiotic prescribing and consumption for urinary tract infections. BMJ Open. 2016;6:e008894.

7. Little P, Everitt H, Williamson I, Warner G, Moore M, Gould C, et al. Observational study of effect of patient centredness and positive approach on outcomes of general practice consultations. BMJ. oct 2001;20(7318):908-11. 323(.

8. Wild DJ, Clayson DJ, Keating K, Gondek K. Validation of a patient-administered questionnaire to measure the activity impairment experienced by women with uncomplicated urinary tract infection: the Activity Impairment Assessment (AIA). Health Qual Life Outcomes. 15 juill 2005;3:42.

9. Slevin ML, Plant H, Lynch D, Drinkwater J, Gregory WM. Who should measure quality of life, the doctor or the patient? Br J Cancer janv. 1988;57(1):109-12. 
10. Holm A, Cordoba G, Siersma V, Brodersen J. Development and validation of a condition-specific diary to measure severity, bothersomeness and impact on daily activities for patients with acute urinary tract infection in primary care. Health Qual Life Outcomes [Internet]. 24 mars 2017;15-57.

11. Kelleher CJ, Cardozo LD, Khullar V, Salvatore S. A new questionnaire to assess the quality of life of urinary incontinent women. BJOG Int J Obstet Gynaecol. 1997;104(12):1374-9.

12. Amarenco $G$, Marquis $P$, Leriche $B$, Richard F, Zerbib $M$, Jacquetin $B$. Une échelle spécifique d'évaluation de la perturbation de la qualité de vie au cours des troubles mictionnels: l'échelle Ditrovie. Ann Réadapt Médecine Phys. 1 janv 1997;40(1):21-6.

13. Brazier JE, Harper R, Jones NM, O'Cathain A, Thomas KJ, Usherwood T, et al. Validating the SF-36 health survey questionnaire: new outcome measure for primary care. BMJ. 18 juill 1992;305(6846):160-4.

\section{Figures}

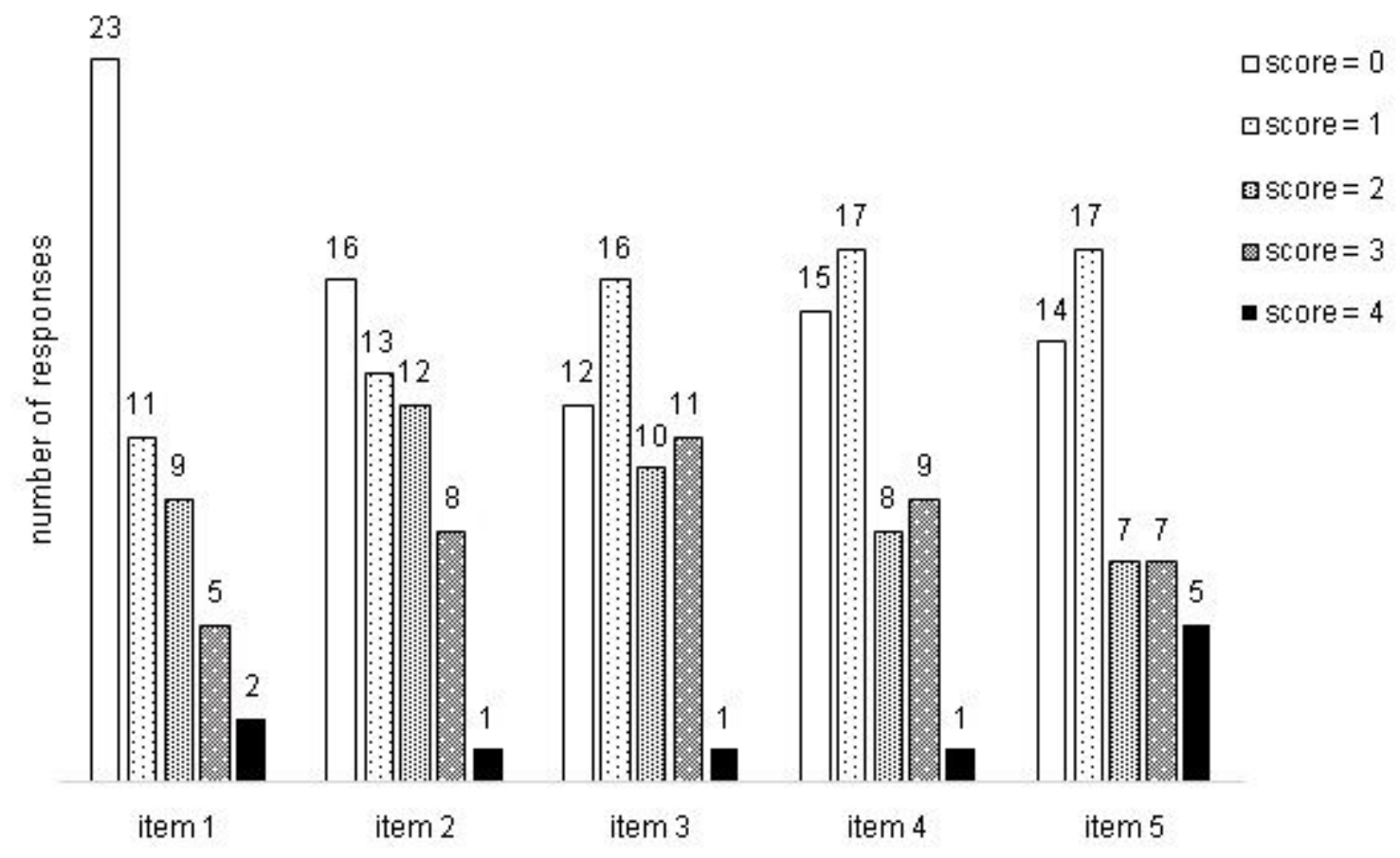

Figure 1

Looking for floor and ceilingeffects in the distribution of AIA-fr items scores at baseline (MSOffice). 


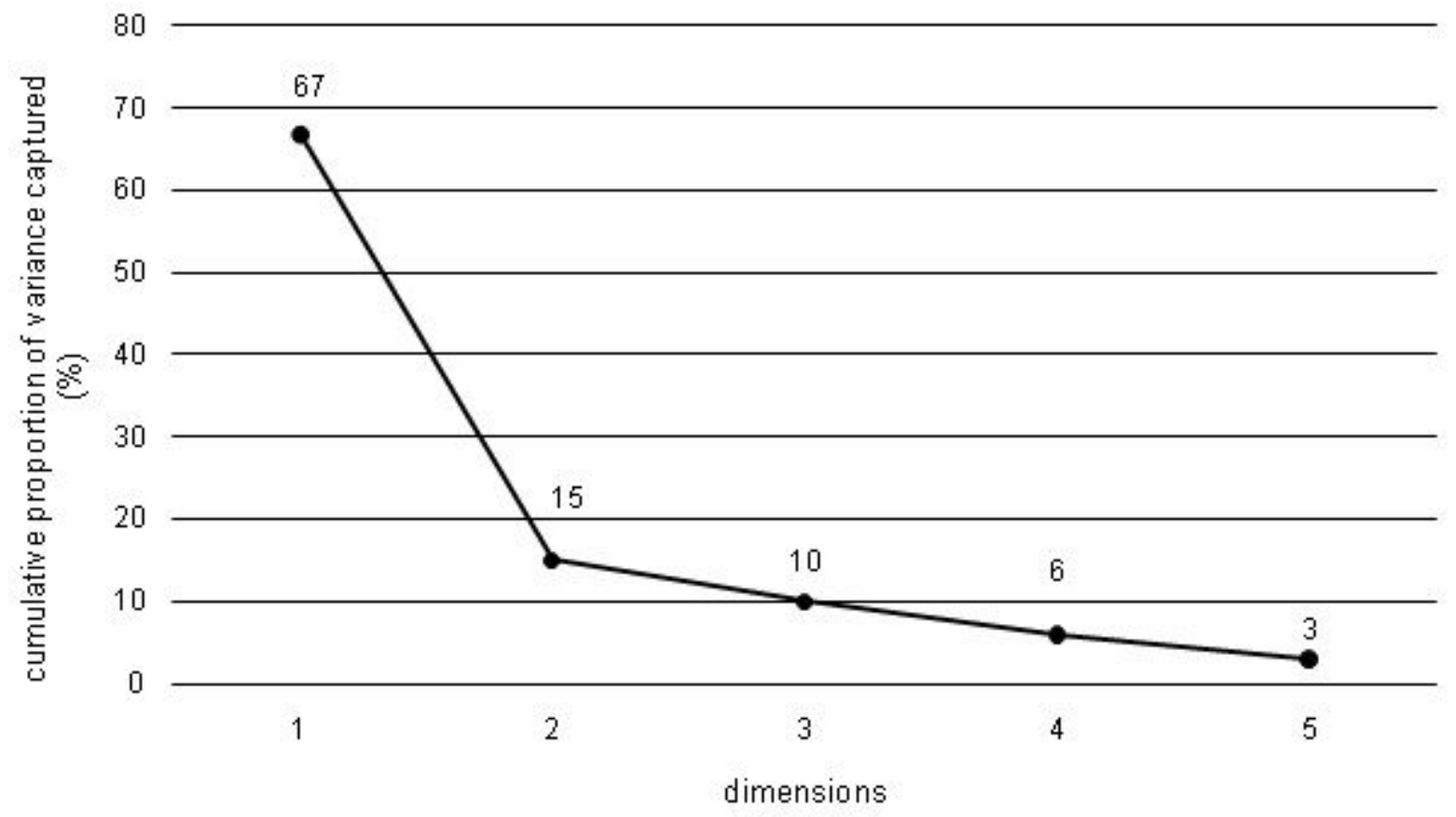

Figure 2

Diagram of Eigenvalues (MSOfficeaccording to R results). 